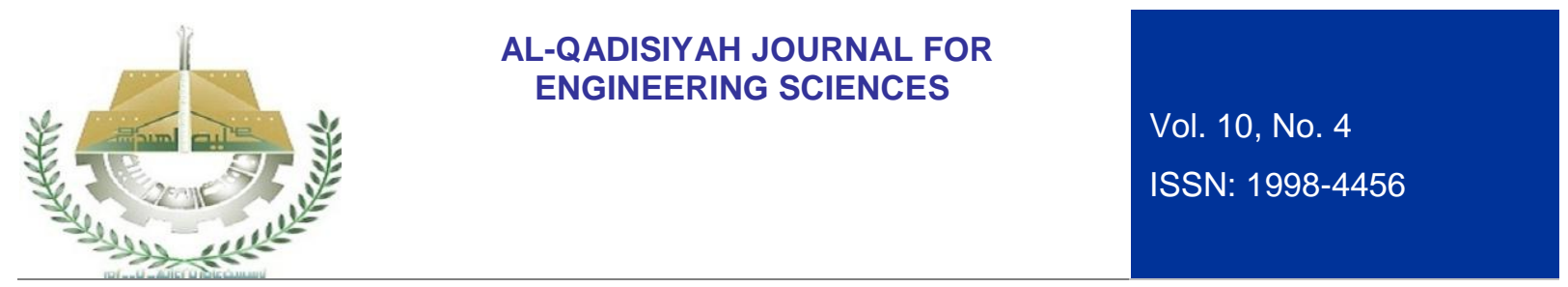

\title{
STRUCTURE-PROPERTIES RELATIONSHIPS IN HEAT TREATED LOW CARBON STEEL
}

\author{
Heider Yasser Thamir Alyasiri, \\ Materials Engineering Dept., College of Engineering, University of Al-Qadisiyah, AL-Diwaniyah, Iraq. \\ E-mail: heider.thamir@qu.edu.iq
}

Received on 6 September 2017 Accepted on 31 October 2017 Published on 15 January 2018 DOI: 10.30772/qjes.v10i4.496

\begin{abstract}
The samples of AISI 1018 Low carbon steel were heated to austenite zone then cooled in different mediums with different cooling rates. Mechanical tests show increase in hardness, yield strength, tensile strength, modulus of elasticity, and yield/tensile ratio as cooling rate is increase. Ductility has inverse proportionality to cooling rate. The resulting microstructures show decreasing in grains sizes accompanying to cooling rate increase. The relations between mechanical properties and grains size are opposites of relations between mechanical properties with cooling rates. Hardness, yield strength, tensile strength, modulus of elasticity, and yield/tensile ratio increase as grains size decreases, while ductility decreases.
\end{abstract}

Keywords: AISI 1018 steel, heat treatment, grain size, Hall-Petch, cooling rate.

\section{INTRODUCTION}

It is obviously clear that iron alloys are the most used through all known metallic and nonmetallic engineering materials. Their widespread use is accounted for by many reasons including overall cost and availability, but the main reason still the versatility, where thier properties -mainly mechanical ones- can be changed through a wide range [1]. This versatility is attributed to chemical compositions modification and/or subsequent heat-treatments and in some times mechanical treatments, which can change the presence, number, shape, size, and distribution of phases through steel structure. Any alteration of microstructure will strongly affect steels properties [2-4]. It's possible to modify microstructure without changing composition through application of heat treatment techniques which may introduce new structures. But, in some cases it's undesirable to change phase and/or composition, or as the case in all pure metals and some of alloys like mild steel where it is unpractical or difficult to alter the presence of phases [5-7]. Here, the useful way to alter the properties using heat treatment is through changing the shape, size and distribution of present phase(s). Among them (shape, size and distribution), controlling grain size is the most efficient, which can greatly affect properties of the part through refining or coarsening of grains. In general, grain size has inverse proportionality with strength and hardness; otherwise, it has direct proportionality with ductility $[8,9,10]$. This proportionality was described generally by Hall-Petch relationship [11]. Controlling grains size can be reached by controlling cooling rate of specified part in heat treatment using different mediums for cooling $[8,9,12]$. Many efforts were dedicated to describe the relation between grain size and the intended property for ferrous and nonferrous alloys [10,13,14]. 


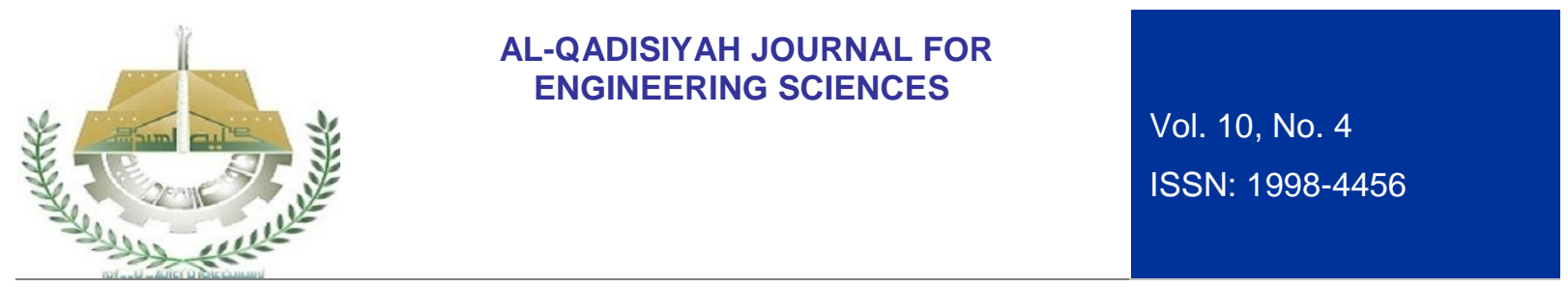

\section{EXPERIMENTAL PROCEDURES}

AISI 1018 Low carbon steel specimens with mechanical properties shown in table 1 were prepared to heat treatment processes. After, they were divided into groups and heated in electrical resistance furnace to a temperature of $910^{\circ} \mathrm{C}$, and held at this temperature for about two hours to ensure heat homogeneity and totally phase change. Then, they were cooled in different cooling mediums including ice cooled water $\left(0.5^{\circ}\right.$ $\mathrm{C})$, tap water $\left(32^{\circ} \mathrm{C}\right)$, machine oil $\left(32^{\circ} \mathrm{C}\right)$, still air $\left(32^{\circ} \mathrm{C}\right)$, and in the heating furnace (turned off and closed). The approximate cooling rates were: icy water $120^{\circ} \mathrm{C} / \mathrm{sec}$, tap water $80^{\circ} \mathrm{C} / \mathrm{sec}$, machine oil $30^{\circ} \mathrm{C} / \mathrm{sec}$, still air $1.25^{\circ} \mathrm{C} / \mathrm{sec}$, and closed furnace $0.125^{\circ} \mathrm{C} / \mathrm{sec}$. The specimens then were ready to be conducted in tensile test, hardness test, and microstructure examination to evaluate properties evolution in accordance with structural changes and attendant cooling rates.

Table 1: Properties of as received AISI 1018 Steel.

\begin{tabular}{|c|c|c|c|c|c|}
\hline $\begin{array}{c}\text { Yield Strength } \\
\text { Mpa }\end{array}$ & $\begin{array}{c}\text { Tensile } \\
\text { Strength MPa }\end{array}$ & $\begin{array}{c}\text { Modulus of Elasticity } \\
\text { Gpa }\end{array}$ & $\begin{array}{c}\text { Hardness HV } \\
\mathrm{Kg} / \mathrm{mm}^{2}\end{array}$ & Ductility \% & $\begin{array}{c}\text { Average Grain } \\
\text { Size um }\end{array}$ \\
\hline 473 & 616 & 237 & 170 & 18 & 7.2 \\
\hline
\end{tabular}

\section{RESULTS AND DISCUSSION}

\subsection{HARDNESS TESTS}

Vickers Hardness results of icy water quenched, water quenched, oil quenched, air cooled, furnace cooled, and as received specimens are ordered descendingly in table 2. Hardness tests were conducted in three regions for each specimen; centre, edge, and middle between them to evaluate hardness change with depth from surface. It can be easily shown that hardness value is greater for a faster cooling medium and vice versa, and hardness for as received specimen is bigger than that for still air and closed furnace mediums, but smaller than other mediums. For each individual specimen the hardness values increase as moving from centre toward the outer surface consistently with increasing cooling rates for regions inside the sample, where the rate of cooling is higher at surface and being lower as the region is approaching the centre of specimen. The difference between hardness of outer surface and inner regions is not at same consistent pattern, difference is bigger for icy cooled medium and nearly equal (no difference) for closed furnace. The reason is that for coldest quenching medium the cooling rates at surface is much higher than inner regions, but, for less cooling mediums the difference will be smaller, and even equal or near equal for very slow cooling medium as the case with closed furnace. Figure 1 represents relation between cooling medium and specimen hardness.

Table 2: Hardness of specimens with cooling mediums for different regions in each specimen. E: edge, M: middle, C: centre.

\begin{tabular}{|c|c|c|c|c|c|c|c|c|c|c|c|c|c|c|c|c|c|c|}
\hline $\begin{array}{l}\text { Cooling } \\
\text { medium }\end{array}$ & \multicolumn{3}{|c|}{ Icy water } & \multicolumn{3}{|c|}{ Tap water } & \multicolumn{3}{|c|}{ Oil } & \multicolumn{3}{|c|}{$\begin{array}{l}\text { As received } \\
\text { (not treated) }\end{array}$} & \multicolumn{3}{|c|}{ Still air } & \multicolumn{3}{|c|}{$\begin{array}{l}\text { Closed } \\
\text { furnace }\end{array}$} \\
\hline Hardness & $E$ & $M$ & $\mathrm{C}$ & $E$ & $\mathrm{M}$ & $\mathrm{C}$ & $E$ & $M$ & C & $E$ & $M$ & C & $E$ & $M$ & C & $E$ & $M$ & $\mathrm{C}$ \\
\hline $\mathrm{HV}$ & 292 & 265 & 259 & 242 & 225 & 220 & 228 & 215 & 209 & 186 & 176 & 170 & 154 & 148 & 144 & 120 & 117 & 117 \\
\hline
\end{tabular}

\subsection{TENSILE TESTS}

Results of tensile tests for the specimens are represented in table 3. Yield strength, tensile strength, and young modulus also strongly depend on cooling rates, in the same way hardness results do. Again, it can be shown that values of yield strength, tensile strength, and modulus of elasticity are higher for a faster cooling medium and vice versa, the values of these properties for as received specimen are bigger than that for still air and closed furnace mediums, but smaller than other mediums (Figure 2). For stiffness which is 


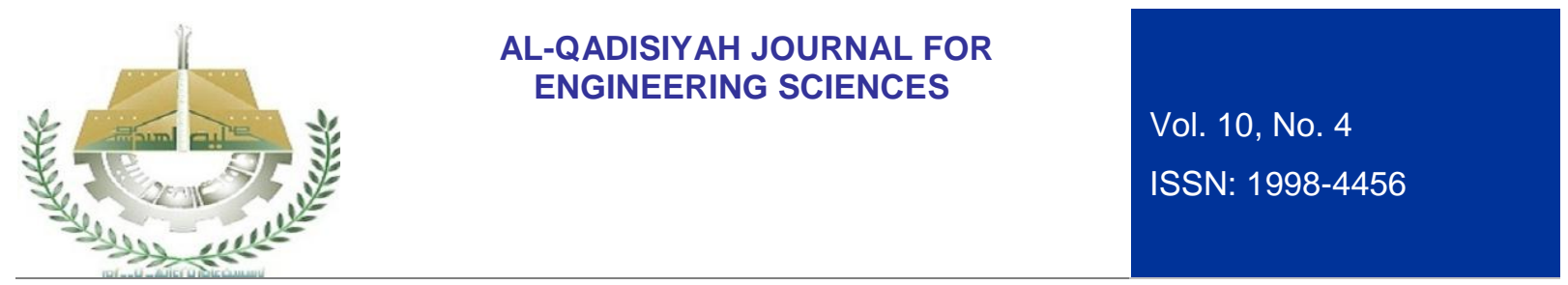

identified by modulus of elasticity (Figure 3), it is evident that it follows the same approach as hardness and strength did, depending on cooling rate and accordingly cooling medium. As cooling is faster as stiffness value is bigger.

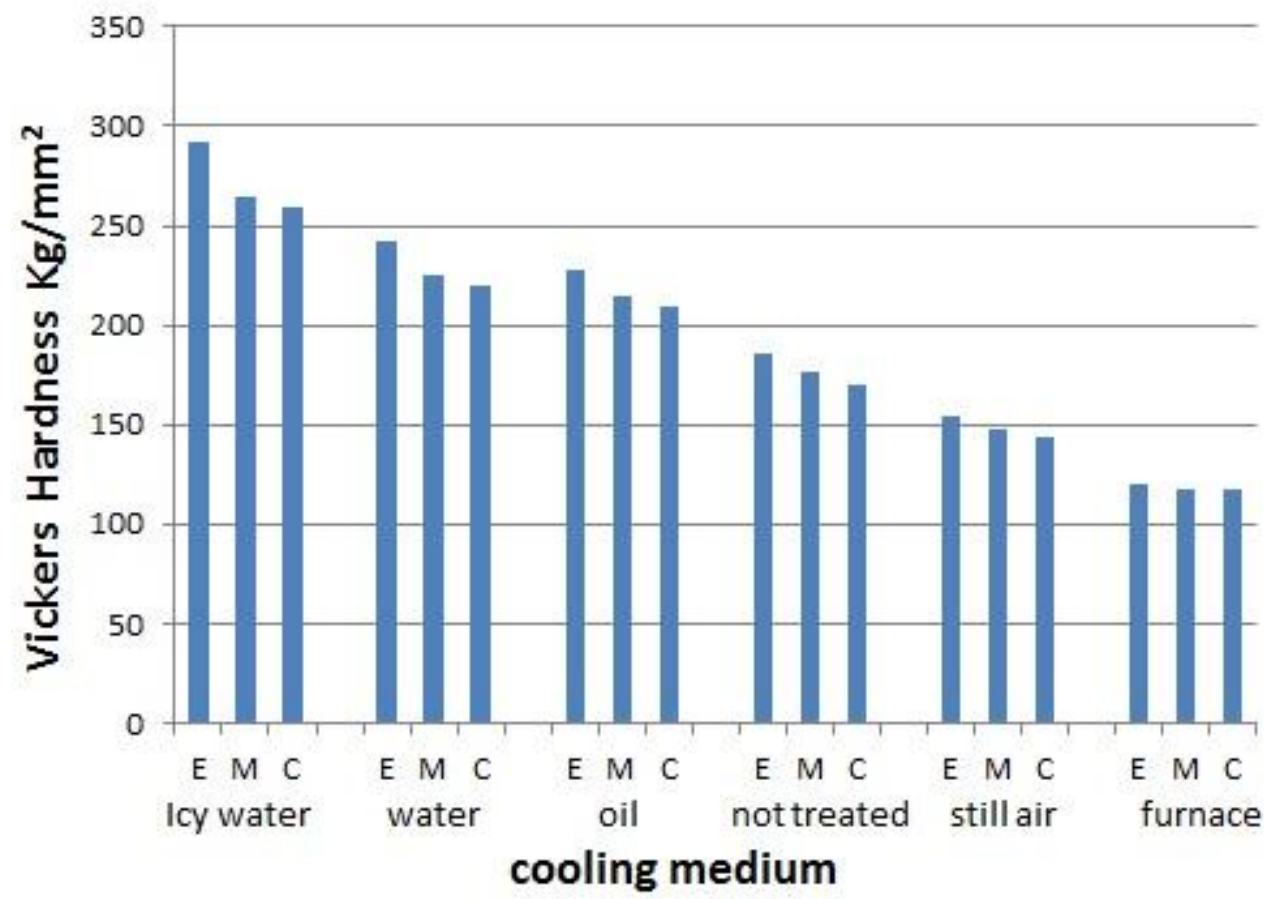

Figure 1: Relation between cooling medium and specimen hardness at edge $(E)$, middle $(\mathrm{M})$, and centre $(\mathrm{C})$, in different cooling mediums.

Table 3: Yield strength, tensile strength, young modulus, yield/tensile strength ratio, and ductility of specimens with different cooling mediums.

\begin{tabular}{|c|c|c|c|c|c|c|}
\hline Cooling medium $\rightarrow$ & $\begin{array}{c}\text { Icy } \\
\text { water }\end{array}$ & $\begin{array}{c}\text { Tap } \\
\text { water }\end{array}$ & Oil & $\begin{array}{c}\text { As received } \\
\text { (not treated) }\end{array}$ & $\begin{array}{c}\text { Still } \\
\text { air }\end{array}$ & $\begin{array}{c}\text { Closed } \\
\text { furnace }\end{array}$ \\
\hline Yield strength Mpa & 806 & 553 & 513 & 473 & 316 & 271 \\
\hline Tensile strength Mpa & 830 & 674 & 637 & 616 & 438 & 397 \\
\hline Young modulus Gpa & 403 & 277 & 257 & 237 & 158 & 136 \\
\hline Yield/Tensile & 0.971 & 0.82 & 0.805 & 0.768 & 0.721 & 0.683 \\
\hline Ductility \% & 7.7 & 13.6 & 14 & 18.3 & 25 & 42 \\
\hline
\end{tabular}

In opposite direction ductility goes with inverse proportionality to cooling rate and attendant cooling medium (Figure 4). The ductility of as received (not treated) specimen is smaller than that for closed furnace and still air mediums, but is bigger than other mediums. The maximum ductility is for furnace cooled sample, and minimum one is for icy water quenched sample. When notice values of yield/strength ratio (Figure 5), we can recognize that the behavior is the same of hardness, yield, and tensile strength. This factor $(\mathrm{Y} / \mathrm{T})$ is so important for deformation manufacturing processes employing cold working techniques. When value of yield strength is near to that of tensile strength, it means there is little range of plastic deformation. Herein, using this concept we can deduce what sample is more capable to be used in cold working and what one is less useful or even useless. 


\section{AL-QADISIYAH JOURNAL FOR ENGINEERING SCIENCES}

\section{Vol. 10 , No. 4}

ISSN: $1998-4456$

\subsection{MICROSTRUCTURE EXAMINATION}

The microstructure is examined and analyzed to determine grains size of phases. Typically, in low carbon steel the existing phases are ferrite as a major and pearlite as a minor. Using photos obtained from optical microscopy and applying line intercepts method, the grain size is determined for every specimen. Grains sizes are given in table 4 . The microstructure photos of icy water quenched, water quenched, oil

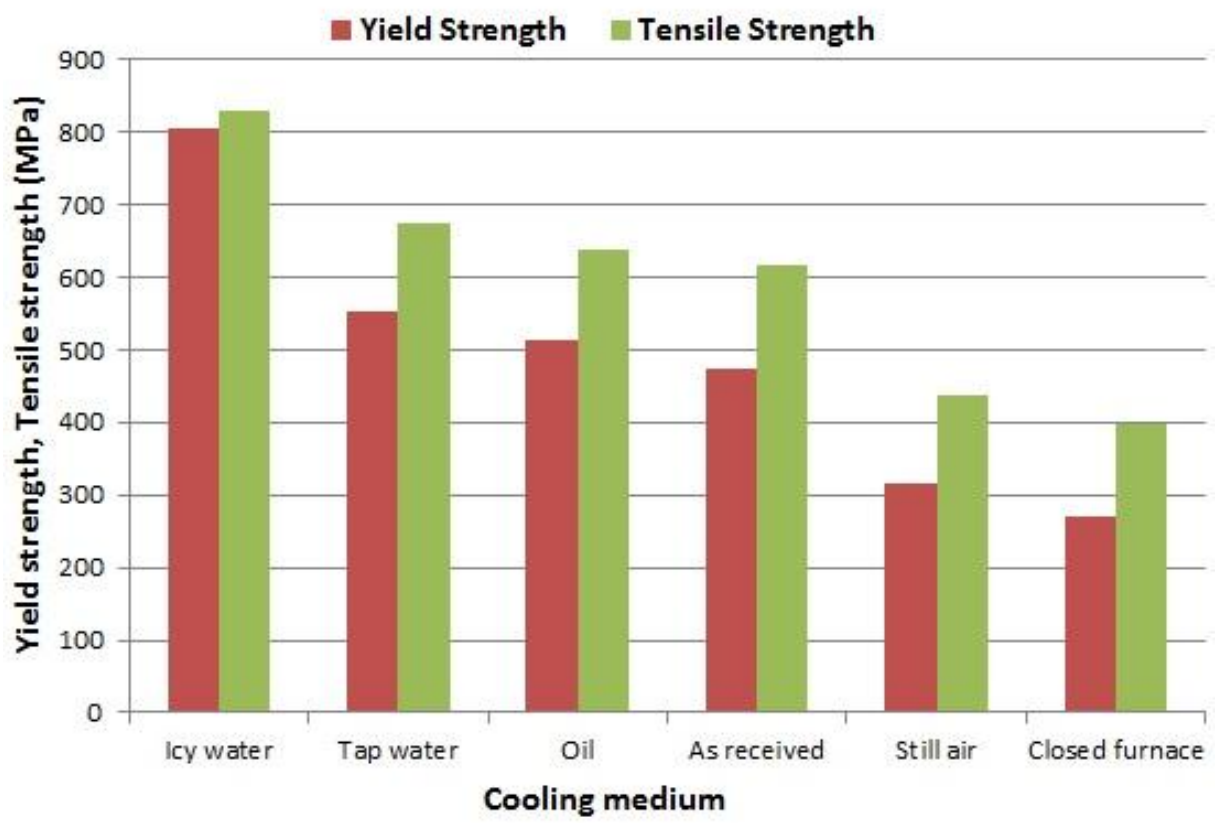

Figure 2: Cooling medium - yield and tensile strength relationship.

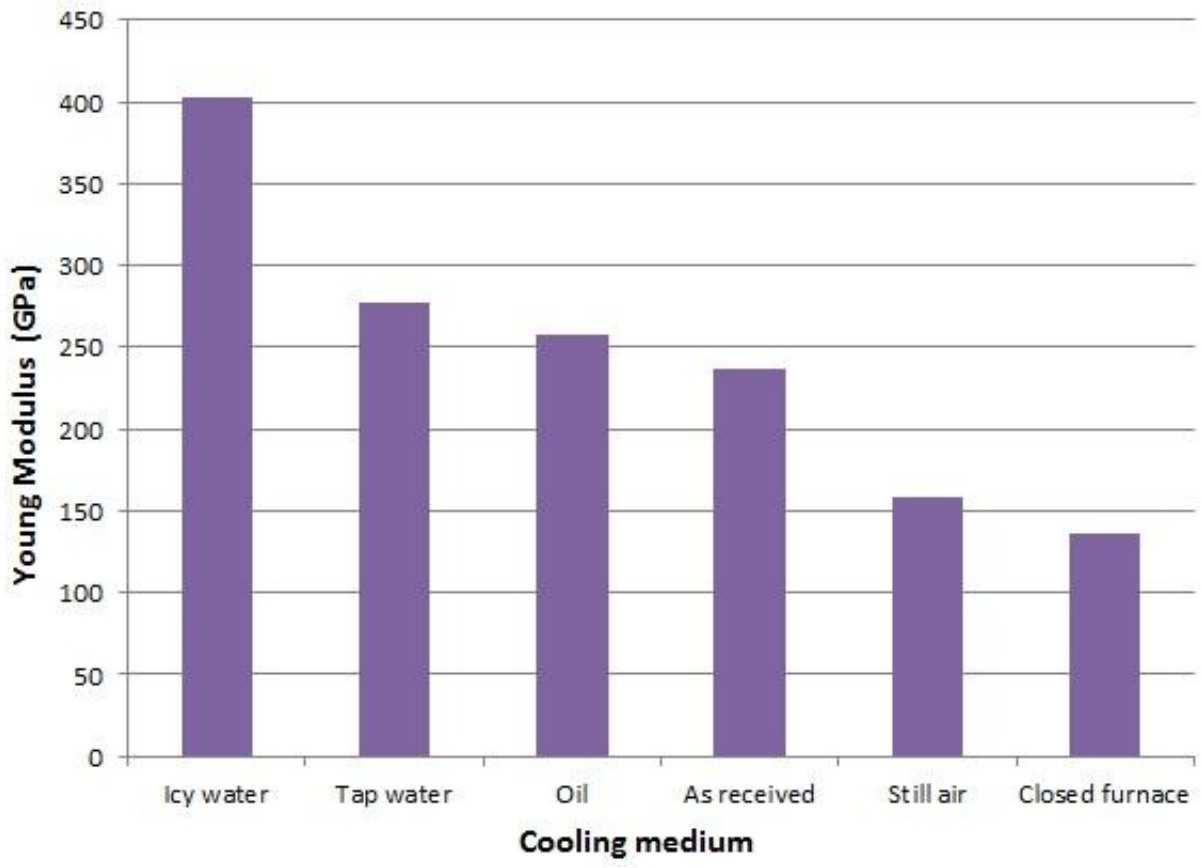

Figure 3: Cooling medium - young modulus relationship. 


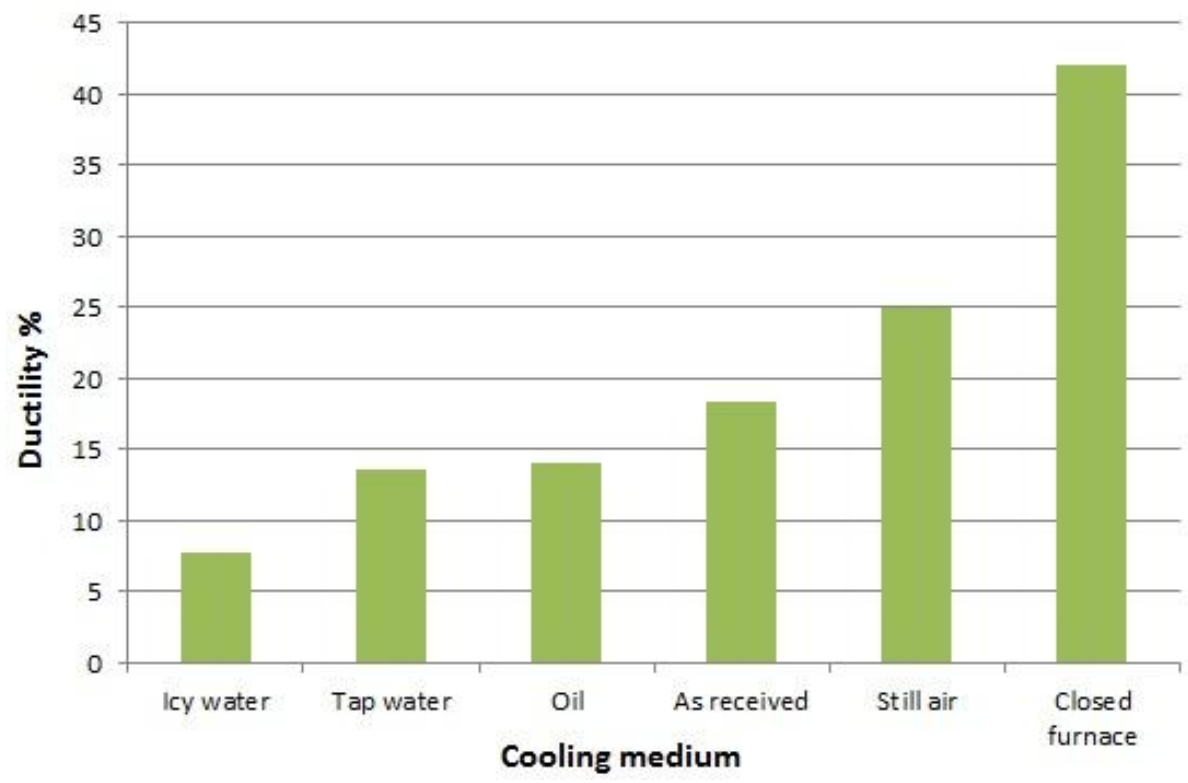

Figure 4: Cooling medium - ductility relationship.

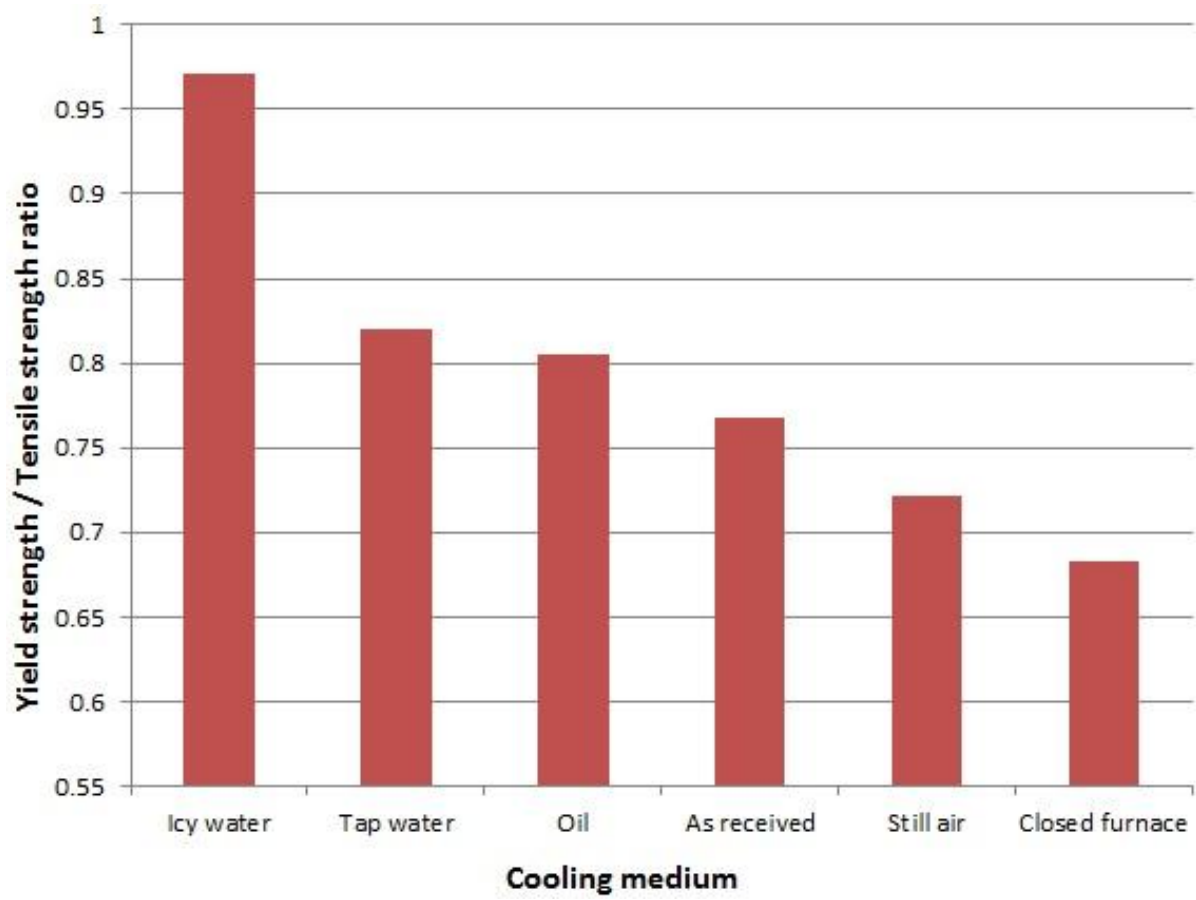

Figure 5: Cooling medium $-\mathrm{Y} / \mathrm{T}$ ratio relationship.

Table 4: Grains sizes of specimens according to cooling mediums.

\begin{tabular}{|c|c|c|c|c|c|c|}
\hline $\begin{array}{c}\text { Cooling } \\
\text { medium }\end{array}$ & Icy water & Tap water & Oil & $\begin{array}{c}\text { As received } \\
\text { (not treated) }\end{array}$ & Still air & Closed furnace \\
\hline $\begin{array}{c}\text { Grains sizes } \\
\text { (micrometers) }\end{array}$ & 4.3 & 5.4 & 6.5 & 7.2 & 10.7 & 17 \\
\hline
\end{tabular}




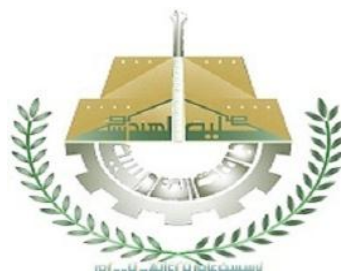

\section{AL-QADISIYAH JOURNAL FOR ENGINEERING SCIENCES}

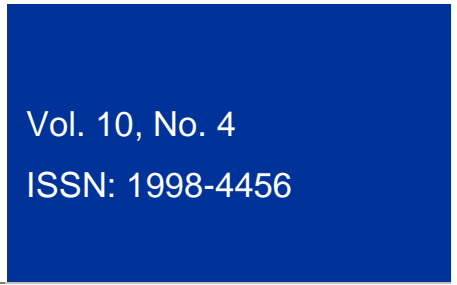

quenched, non-treated, air cooled, and closed furnace cooled specimens are given respectively in $A, B, C$, $D, E$, and $F$ in figure 6 . The real width of each photo is 227 micrometers. Pearlite and ferrite fractions are not the same in all specimens even though they were cut from the same bar, since we can see that as cooling rate increases the pearlite content increases in expense of ferrite (even little), this is because that the non equilibrium conditions encourage pearlite nucleation. The size of grains already inversely proportionates to cooling rate and its corresponding cooling medium, as demonstrated in figure 7.
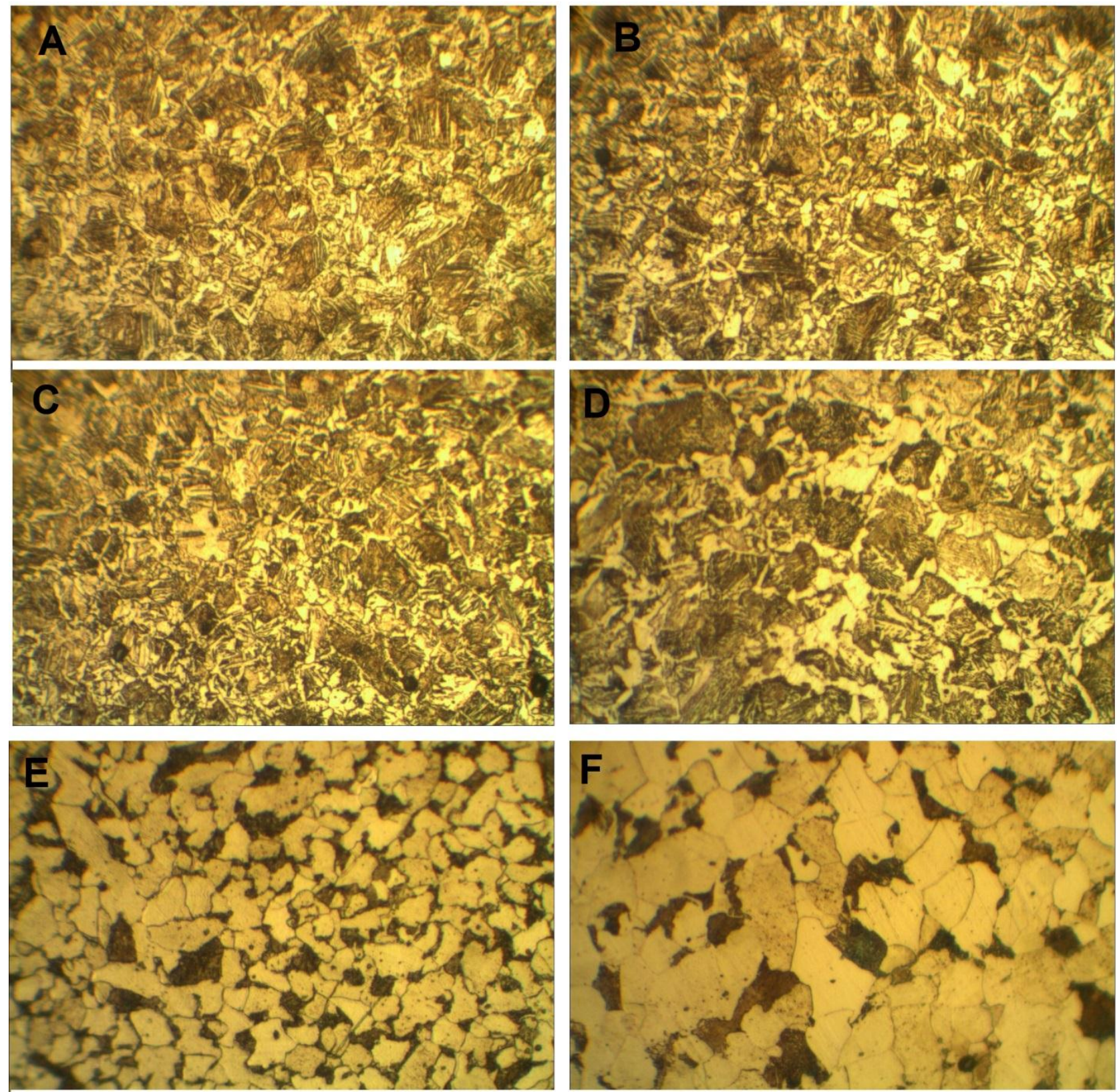

Figure 6: Icy water quenched $(A)$, water quenched $(B)$, oil quenched $(C)$, non-treated $(D)$, air cooled $(E)$, and closed furnace cooled $(\mathrm{F})$. 

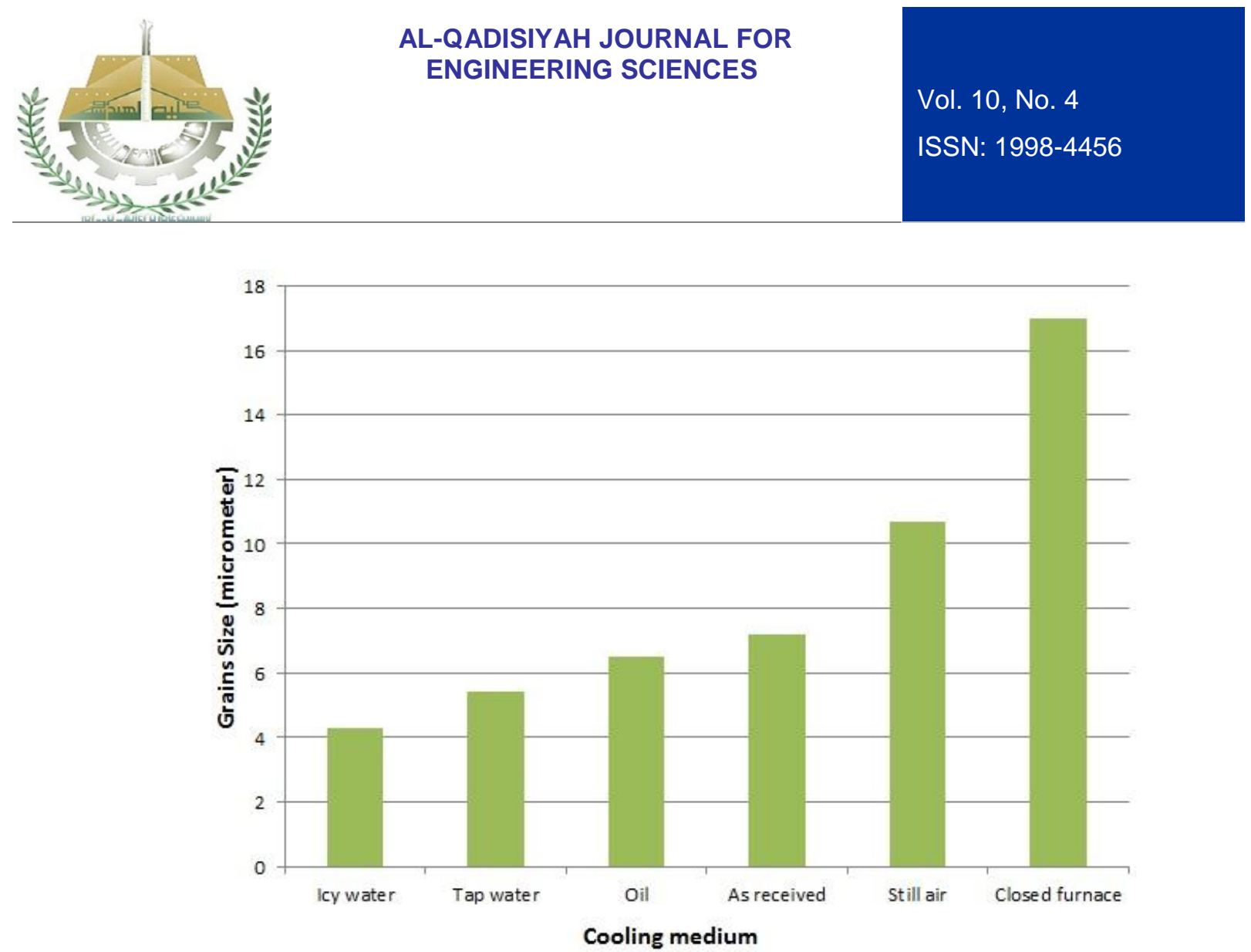

Figure 7: Cooling medium - grains size relationship.

The mean of hardness (Figure 8), yield strength, and tensile strength (Figure 9) proportionate inversely to grains size, and also the modulus of elasticity does (Figure 10). To explain this we need to remember that the main mechanism for strengthening metals and alloys is by hindering dislocations movement, and grain boundaries are one of obstacles that impede this motion. On the other hand it is well known that the total area of grains boundaries increases as grains sizes decrease, and as a consequent the movement of dislocations will be inhibited (partially), leading to apparent improvements on strength and hardness of the alloy, also the increasing of pearlite fraction with increasing cooling rate leads to increase in strength and hardness (pearlite is stronger than ferrite). Also decreasing grains sizes lead to decreasing ductility (Figure 11). It also can be explained. Simply, fine grained crystal has more hinderence to dislocations in the form of grain boundaries, and the available volume for dislocations movements is greatly reduced leading to ductility reduction, with regard to that increasing pearlite fraction also helps in decreasing ductility (pearlite is less ductile than ferrite). At opposite direction, as the size of grain is bigger as the slip

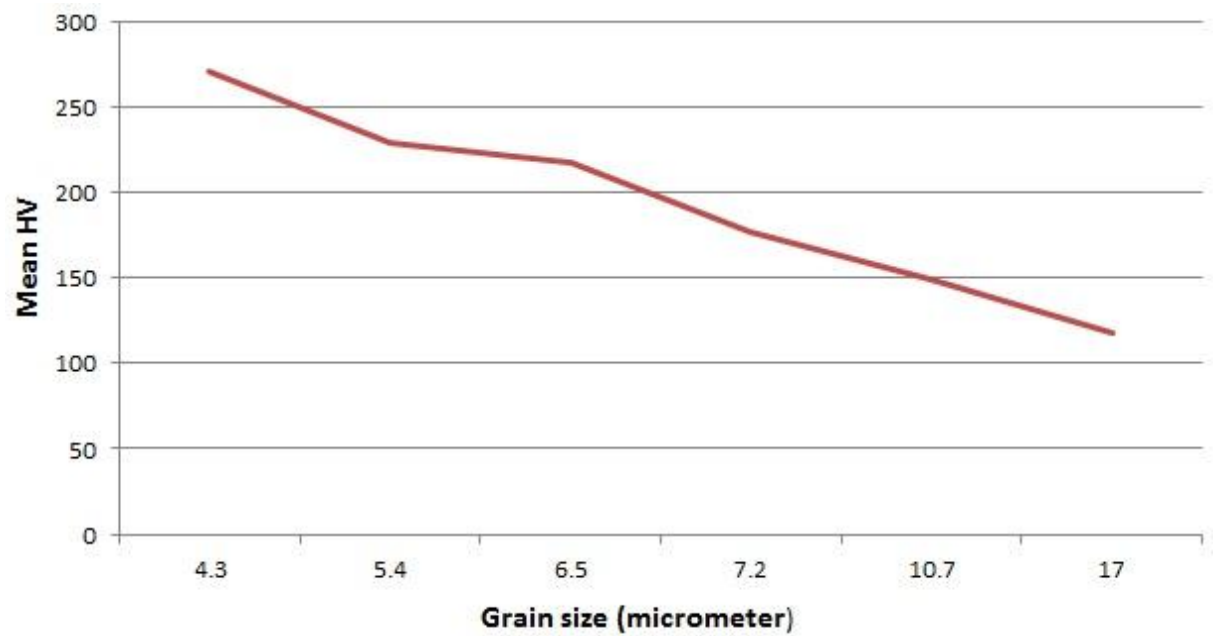

Figure 8: Grains size - mean hardness relationship. 


\section{AL-QADISIYAH JOURNAL FOR ENGINEERING SCIENCES}

\section{Vol. 10, No. 4}

ISSN: $1998-4456$

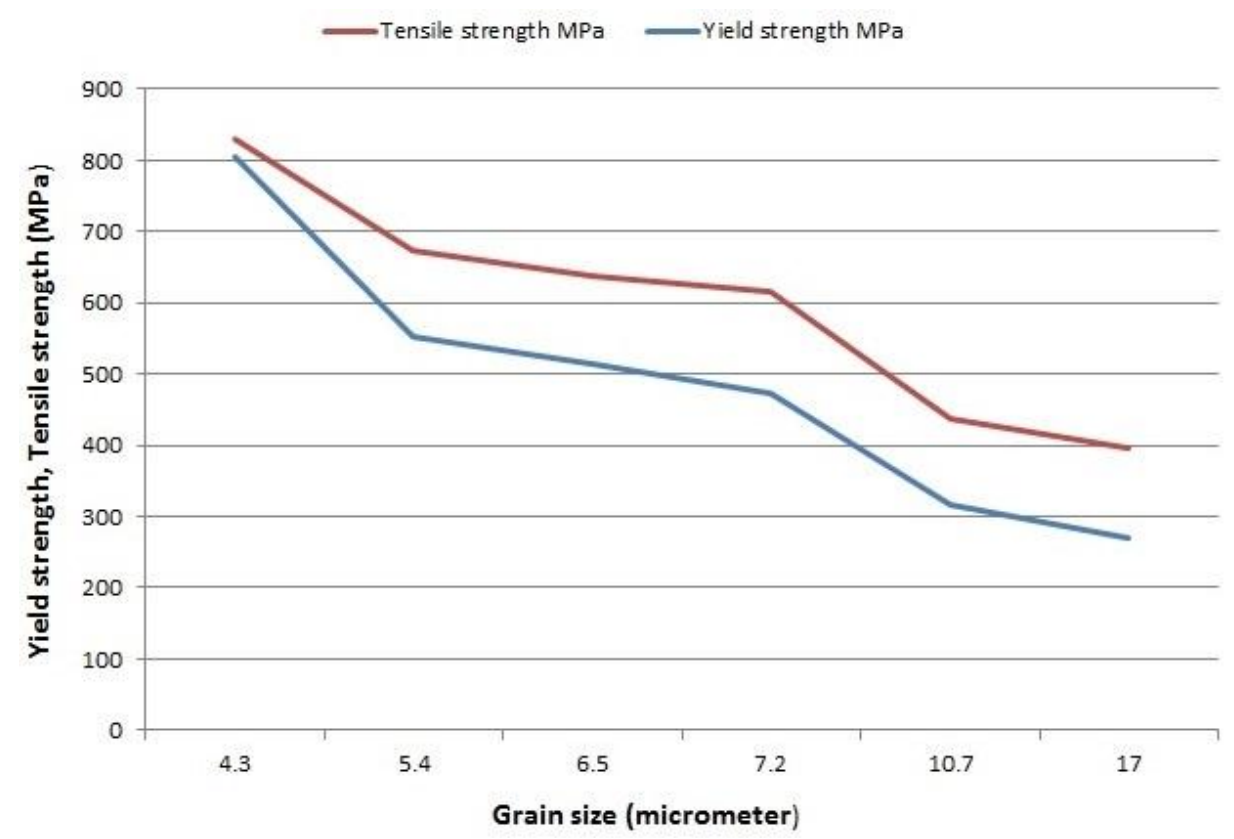

Figure 9: Grains size - yield strength, tensile strength relationship.

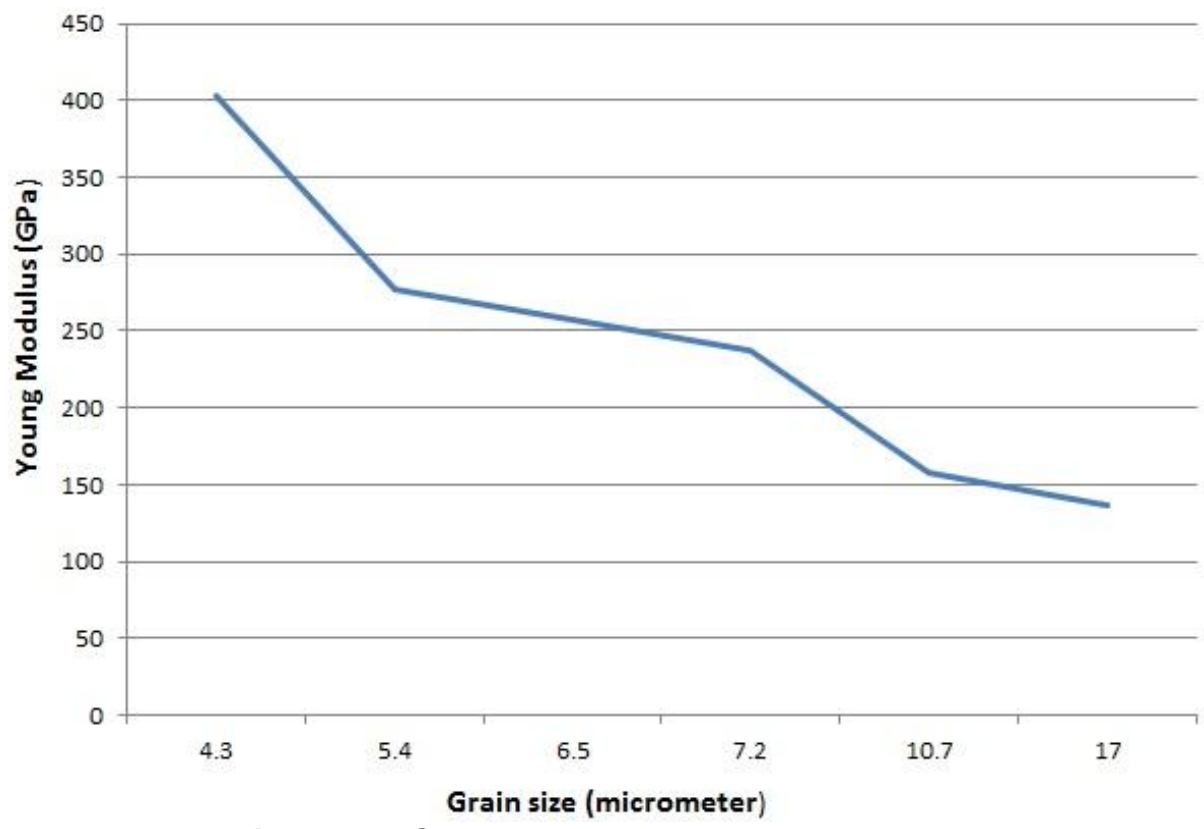

Figure 10: Grains size - young modulus relationship.

planes are continued through long distances permitting the dislocations to move and metal to deform more with less disrupting (less dislocations pileup at grain boundaries) leading to more ductility, also with regard to increasing ferrite fraction that helps in increasing ductility. According to increase strength and decrease ductility with decreasing grain size, it's reasonable that (yield strength / tensile strength) ratio will increase as grain size decreases (Figure 12). 


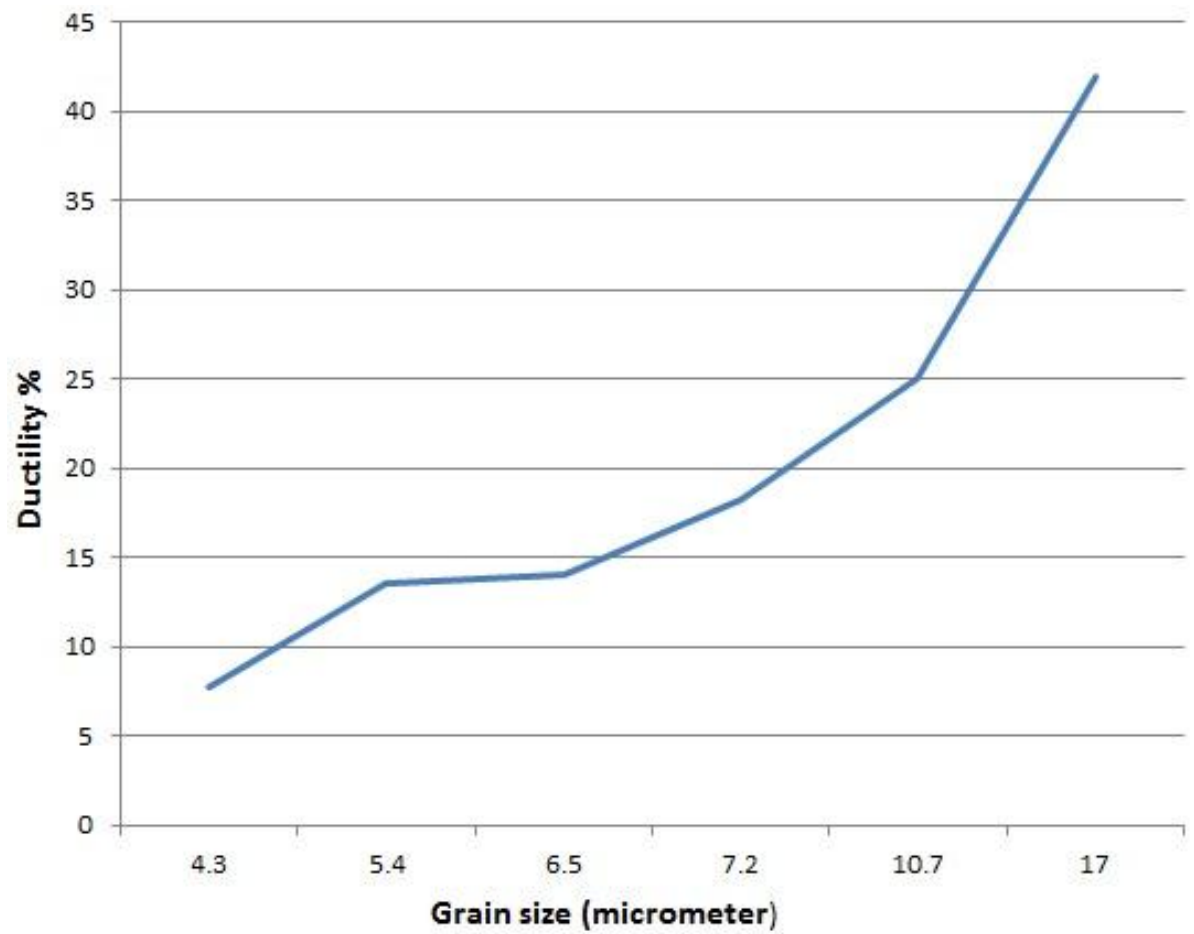

Figure 11: Grains size - ductility relationship.

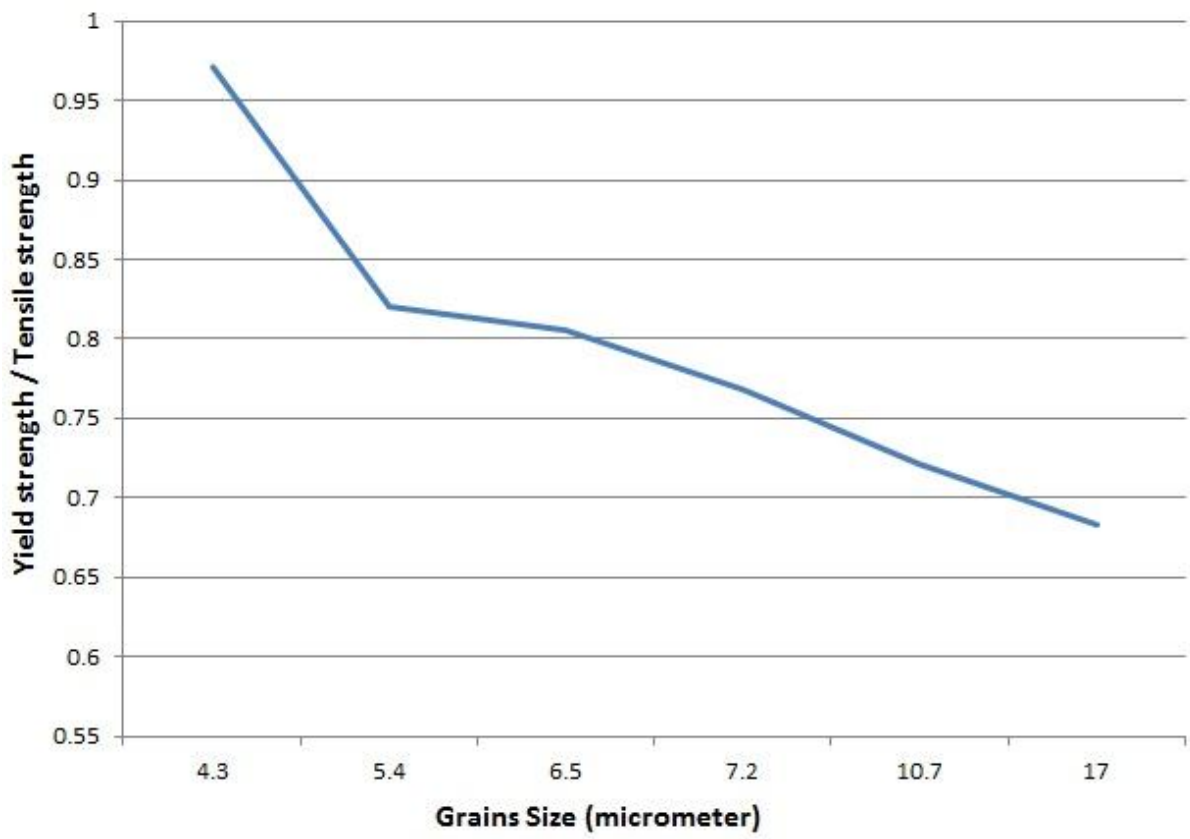

Figure 12: Grains size $-\mathrm{Y} / \mathrm{T}$ ratio relationship.

\section{CONCLUSIONS}

1. Hardness of treated part increases or decreases as the cooling medium has more or less cooling rate (compared with other mediums).

2. In one specimen the hardness of the outer surface is higher than inner regions. And as the cooling being faster as the difference being bigger. 


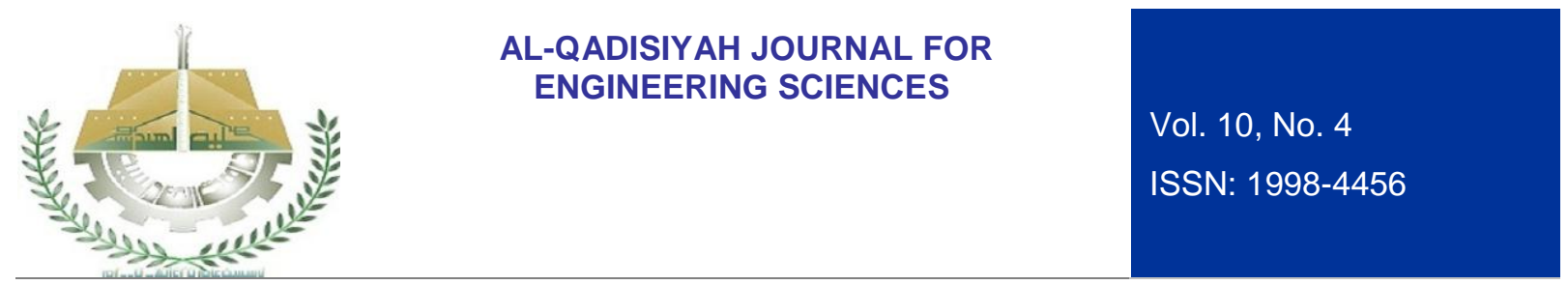

3. Yield strength, tensile strength, and stiffness proportionate directly with cooling rates. But ductility has invers proportionality to cooling rates.

4. Yield strength / tensile strength ratio increases as the cooling rate increases, indicating decreasing in cold working ability.

5. As cooling rate increases as the resulting structure has finer grain size, and vice versa.

6. Hardness, yield strength, tensile strength, and stiffness increase with decreasing grains sizes.

7. Increasing grains sizes will decrease ductility.

\section{REFERENCES}

1. William D. Callister, David G. Rethwisch, "Fundamentals of Materials Science and Engineering", John Wiley\& Sons Inc., 2012.

2. Peet, M.J., Babu, S.S., Miller, M.K. et al., "Tempering of Low-Temperature Bainite", Metallurgical and Materials Transactions A, April 2017, Volume 48, Issue 7, pp. 3410-3418.

3. Hallberg, H., Adamski, F., Baïz, S. et al., "Microstructure and Property Modifications of Cold Rolled IF Steel by Local Laser Annealing", Metallurgical and Materials Transactions A, July 2017. https://doi.org/10.1007/s11661-017-4210-y.

4. S. S. Sharma, K. Jagannath, C.Bhat et al., "Effect of Heat Treatment on Mechanical Properties of AISI 4147 Spring Steel", 3rd International Conference on Mechanical, Automotive and Materials Engineering (ICMAME'2013) April 29-30, 2013 Singapore.

5. J. Adamczyk , A. Grajcar, "Heat treatment and mechanical properties of low-carbon steel with dualphase microstructure", Journal of Achievements in Materials and Manufacturing Engineering, Volume 22 Issue 1 May 2007.

6. O.H. Ibrahim, "Comparison of Impact Properties for Carbon and Low Alloy Steels", J. Mater. Sci. Technol., 2011, 27(10), 931-936.

7. Cullen M. Moleejane, Kazeem O. Sanusi, Olukayode L. Ayodele et al., "Microstructural Features and Mechanical Behaviour of Unalloyed Medium Carbon Steel (EN8 Steel) after Subsequent Heat Treatment", Proceedings of the World Congress on Engineering and Computer Science 2014 Vol II WCECS 2014, 22-24 October, 2014, San Francisco, USA.

8. Adnan Çalik, "Effect of cooling rate on hardness and microstructure of AISI 1020, AISI 1040 and AISI 1060 Steels", International Journal of Physical Sciences Vol. 4 (9), pp. 514-518, September, 2009.

9. Md Israr Equbal, Parwez Alam, Rajkumar Ohdar et al., "Effect of Cooling Rate on the Microstructure and Mechanical Properties of Medium Carbon Steel', International Journal of Metallurgical Engineering 2016, 5(2): 21-24.

10. B.Q. Shi, R.S. Chen, W. Ke, "Influence of grain size on the tensile ductility and deformation modes of rolled Mge1.02 wt.\% Zn alloy", Journal of Magnesium and Alloys, 1 (2013) 210-216.

11. Hall, E.O., "The Deformation and Ageing of Mild Steel: III Discussion of Results". Proceedings of the Physical Society, Section B, Volume 64, Number 9, 1951.

12. A.I. Zakya, A. EI-Morsyb, T. El-Bitar, "Effect of different cooling rates on thermomechanically processed high-strength rebar steel", journal of materials processing technology, 209 ( 2009 ) 1565-1569.

13. K.T. Kashyap, T. Chandrashekar, "Effects and mechanisms of grain refinement in aluminum alloys", Bulletin of Materials Science, vol 24, August 2001.

14. Fan, Z.; Wang, Y.; Zhang, Y. et al., "Grain refining mechanism in the Al/Al-Ti-B system", Acta Materialia, 84: 292-304, 2015. 